\title{
Optimizing World-wide Utilization of Renewable Energy Sources in the Power Sector
}

\author{
Tino Aboumahboub ${ }^{1}$, Peter Tzscheutschler ${ }^{1}$, Thomas Hamacher ${ }^{2}$ \\ ${ }^{1}$ Faculty of Electrical Engineering, Institute for Energy Economy and Application Technology \\ Technische Universität München, Arcisstrasse 21, 80333 München, Germany \\ Phone: (+49) 89289 28301, E-Mail: tino.aboumahboub@tum.de, ptzscheu@tum.de \\ ${ }^{2}$ Research group for Energy and Systems Studies, Max Plank Institute for Plasma Physics \\ Boltzmann strasse 2, D-85748 Garching, München, Germany \\ E-Mail: thomas.hamacher@ipp.mpg.de
}

\begin{abstract}
In view of resource scarcity and environmental issues, transition of the current energy system towards a renewable-based supply seems to be a necessity. The interesting questions within this framework are how such a renewablebased energy system should be structured, and how costly it might be. We investigated the optimal structure of a prospective renewable-based power supply system on the world wide scale. This paper describes the applied simulation technique, which integrates an adequately precise geographical coverage with high temporal resolution. This methodology provides the requirements to properly mimic the geographical dependencies of energy supply and demand as well as short term intermittent patterns of renewable sources. A linear optimization algorithm determines the cost optimal configuration of the prescribed energy system.
\end{abstract}

\section{Key words}

Renewable Energy, Simulation, Linear Optimization, Power Supply, Geographic Information System (GIS)

\section{Introduction}

The increasing demand for fossil fuels in the power sector, security of supply and global environmental issues necessitate the transition of the current energy system towards a renewable-based supply. However, integration of renewable energy sources to the power system will result in challenging issues mainly due to the natural intermittent patterns. Therefore, it is necessary to investigate this issue in a systematic simulation-based analysis. The interesting questions within this framework are how such a renewable-based energy system should be structured, and how costly it might be.

The modeling approach presented here is the combination of an adequately precise geographical coverage with high temporal resolution. This methodology provides the requirements to properly mimic the geographical dependencies of energy supply and demand as well as short term intermittent patterns of renewable sources. This methodology is applied here to investigate the long term evolution of the electricity sector on the global level. The model is applied to study how, in a prospective energy supply infrastructure, the transport of electricity between continents, timezones and hemispheres allows gaining profit from interseasonal and interdiurnal variations of renewable energies.

The paper is divided in six parts. In section two the applied methodology is elaborated. Section three describes the developed database. Optimization results for different scenarios are presented in the fourth section. In the last part a summary of results are given, and conclusions are drawn.

\section{Model Framework and Analysis Methodology}

Long-term power generation and transmission investment planning tool, URBS, has been applied here as a framework for developing the model of electricity supply system on the world-wide scale. Simulation has been performed with hourly temporal resolution. The optimization algorithm is based on the concepts of linear programming with an economic objective function, representing the overall system cost:

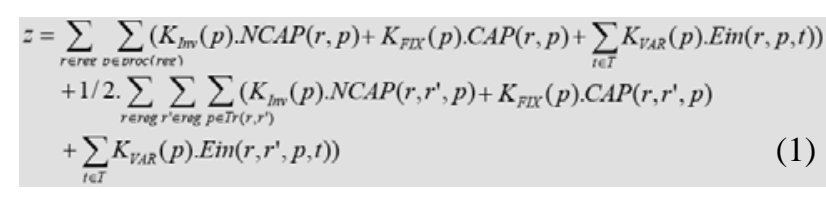

CAP describes the total installed capacity while NCap represents the newly invested power production, storage, and transport technologies available at each region. Ein is the energy input in process $p$ operating in region $r$ at time step t. $\mathrm{K}_{\text {Inv,Fix;var }}$ are the annuity of the investment, fixed and variable costs. Minimization of the overall system 
cost is subject to restrictions, describing the energy system structure at each simulation step. These restrictive equations comprise the supply-demand balance as well as energy conversion, transport, and storage losses, and technical limits of power plants (see [1,2,3]). Model formulation and optimization process is realized with the application of General Algebraic Modeling System (GAMS) software package [4].

Optimal power generation capacities, promising sites for installation of renewable technologies as well as interregional transport capacities result from the optimization process.

A brief overview on the general structure of the model is presented in Fig.1. As it is illustrated in the diagram, hourly time series of GIS-based meteorological data and electrical load profiles, rescaled to a consistent spatial resolution, are aggregated to provide data for model regions. On the other side, techno-economic parameters of power plants and power transmission lines are feed to the model. Conventional existing as well as newly emerging technologies with associated cost reduction and efficiency improvement trends due to learning effects are considered.

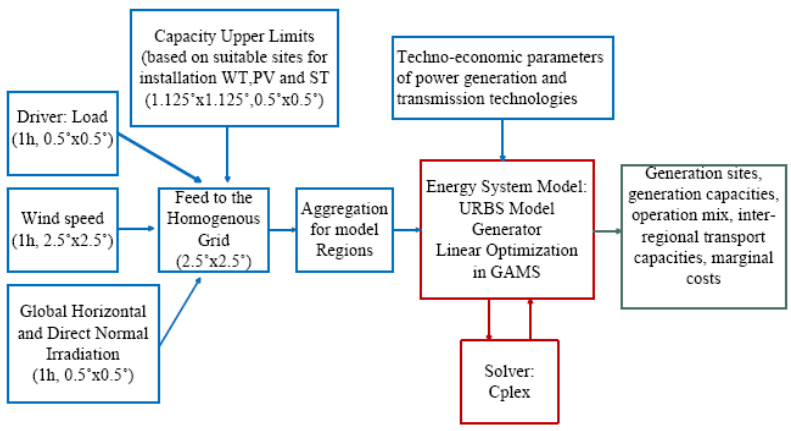

Fig.1. Model Setup

Hourly values of the capacity factor for wind energy converters and solar radiation are considered as constraints on the operation level of renewable technologies. Further restrictions on the permissible level of newly installed capacities are approximated based on the GIS (Geographic Information System) datasets of suitable areas for installation of wind parks and solar thermal power generation systems, described in 3.A and 3.B.

\section{Model Geographical Coverage}

As mentioned in previous sections, modeling at a higher level of spatial as well as temporal resolution is one of the main purposes of the current research. The current model comprises of 51 aggregated regions based on the spatial distribution of technical potential of renewable electricity and the demand. Global multi-regional energy system models (e.g. EFDA TIMES, Multiregional MARKAL and REMIND) are mainly limited to a coarse spatial resolution of up to 15 aggregated regions mainly based on political borders [5,6,7].
Geographical distribution of load and technical potential of renewable electricity is visualized in Fig.2 for each model region. It can be concluded that renewable supply and demand show a rather low geographical correlation. Thus, interregional power transmission plays a key role in this context.

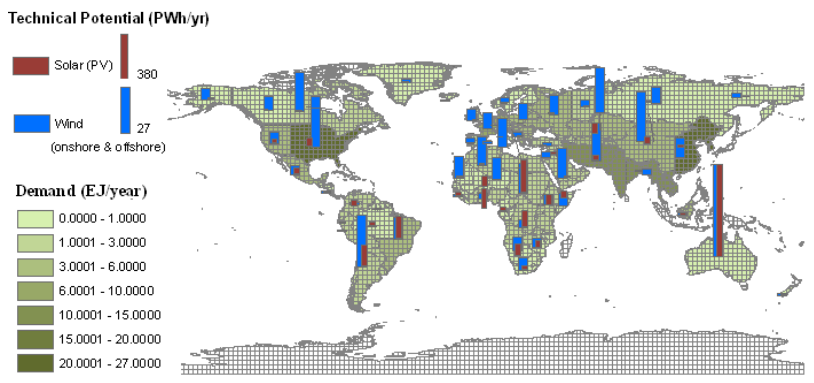

Figure 2. Geographic distribution of electricity demand in 2050 and Renewable Technical Potential, Meteorological data [8,10], Load data [13]

\section{Renewable Energy Supply and Load Data}

\section{A. Solar Energy Potential}

A global dataset of solar irradiance had been produced for SeaWiFS (Sea-viewing Wide Field-of-view Sensor) using data from the International Satellite Cloud Climatology Project (ISCCP). For SeaWiFS production, this data have been mapped on a $720 \mathrm{x} 360\left(0.5^{\circ} \mathrm{x} 0.5^{\circ}\right)$ rectangular grid [8]. The base data includes 3-hourly direct normal and global horizontal irradiance, diffuse fraction and zenith angle values for the time horizon from 1991 to 1993 . We spatially rescaled this dataset for a homogenous grid with a resolution of $2.5^{\circ} \times 2.5^{\circ}$ and approximated the hourly values.

Total capacity permissible to be installed at each grid cell is as well approximated. This has been performed by spatial rescaling of the dataset of available area for installation of solar thermal systems based on the detailed analysis of the global technical potential of solar thermal electricity [9]. For instance, resulting values for the annual specific global horizontal radiation on land sites are visualized in Fig.3.

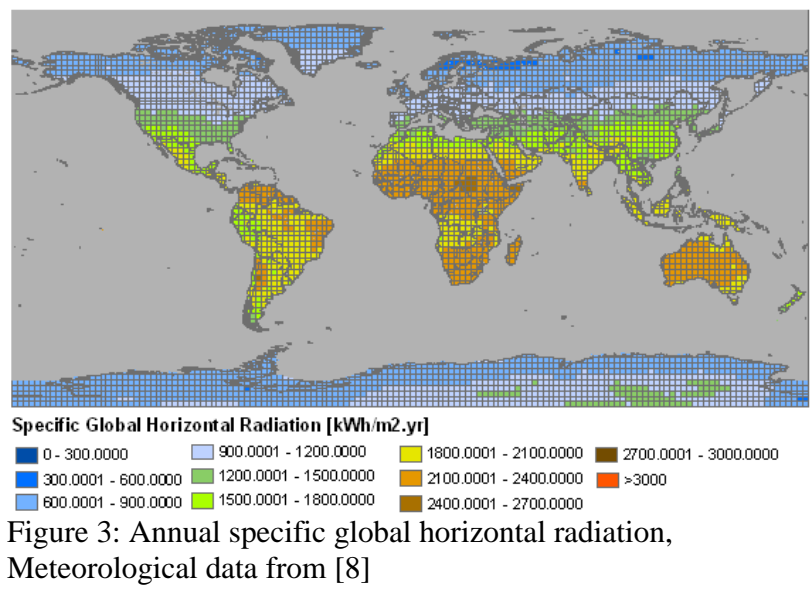




\section{B. Wind Energy Potential}

A global dataset of wind velocities had been provided by World Wind Atlas [10]. Based on measured values, this dataset offer modeled wind speeds for a grid with a resolution of $2.5^{\circ} \times 2.5^{\circ}$. The base data represent six-hour wind speed values for the time horizon from 1992 to 2001 at 50 meters above the ground. For the purpose of modeling with high temporal resolution, hourly values are approximated. The transformation from wind velocity to active power output has been done using data from modern existing wind turbines for onshore and offshore sites [11].

Approximation of regional permissible area for installation of wind parks has been performed by spatial rescaling of the dataset prepared for a grid with a resolution of $1.125^{\circ} \mathrm{x} 1.125^{\circ}$ from the elaborate analysis of global technical potential of wind energy by O.Brückl [12]. One result of the calculation is the annual wind energy production on suitable land sites in full load hours of wind turbine V90-3.0 MW, which is illustrated in Fig.4.

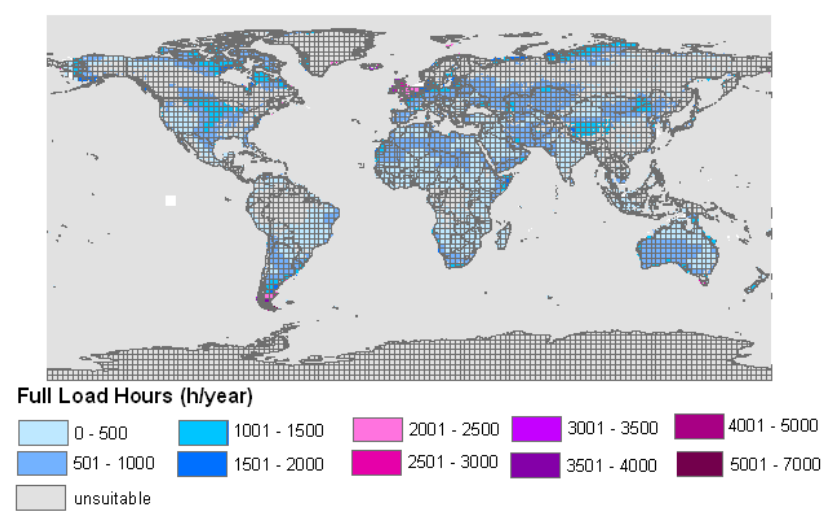

Fig.4. Realizable annual wind energy production on suitable land sites in full load hours of WT: V90-3.0 MW [11], Meteorological data [10] , Site Analysis [12]

\section{Load Data}

Spatially explicit scenario interpretations of population for the time period 1990 to 2100 based on three scenarios (A2, B1, and B2) from the IPCC Special Report on Emissions Scenarios (SRES) are available at IIASA Greenhouse Gas Initiative (GGI) database [13]. To derive unique values for each grid cell, electricity demand from IIASA Greenhouse Gas Initiative (GGI) database has been spatially disaggregated. This has been done based on the spatial distribution of population and applying statistical techniques.

Hourly load data for all UCTE members for the time period 2006 to 2009, Nordel interconnected area and United Kingdom are available at $[14,15]$. Load values for other regions have been provided by personal communications with local transmission system operators $[16,17]$. Eventually, Hourly load data for the year 2007 were made available for 32 countries. For a number of countries comprising Malaysia, Uganda, Thailand, Mali, Niger, Jordan, Australia, Lebanon, and Tunisia we could only gain access to average monthly or typical daily load curves for winter and/or summer. The hourly load values for each model region are approximated based on the linear combination of existing normalized load curves shifted for relevant time zones. Although this procedure will not fit the actual demand pattern, it will serve the purpose to get a rather appropriate estimation of load patterns and to deal with data inadequacy.

\section{Scenario-based Analysis}

\section{A. $100 \%$ Renewables Scenario}

The starting point for the analysis of system behavior is the so-called $100 \%$ renewables scenario. This is considered as an ideal case for the prospective electricity supply system, entirely relying on renewable energies. In ideal scenarios, there is a schematic representation of a conventional power generation technology named “'other"' for providing backup power. As promising options for renewable electricity production, wind energy converters for onshore and offshore sites, centralized PV, Fuel cells, and concentrating solar power systems are considered. The optimization leads to determine the maximal feasible share and the ideal mix of renewable electricity production to provide the least cost solution for satisfying the world-wide electricity demand.

Several boundary conditions such as transmission costs and losses, available storage options and capacities for different regions, fuel prices, and climate policies may have significant impacts on the optimal structure. Through scenario-based analysis and combination of the mentioned boundary conditions, the sensitivity of the results to external factors is investigated. Ideal scenarios and underlying assumptions are presented in Table 1.

Table 1: Ideal scenarios and underlying assumptions

\begin{tabular}{|c|c|}
\hline Scenario & Underlying Assumptions \\
\hline LinkHVDC-NoSto & $\begin{array}{l}\text { - High cost reduction and efficiency } \\
\text { improvement assumed for renewable } \\
\text { technologies } \\
\text { - Suitable and limited suitable sites } \\
\text { can be utilized for renewable } \\
\text { electricity production. } \\
\text { - Supply area is interconnected via } \\
\text { HVDC with low investment cost } \\
\text { based on [18] }\end{array}$ \\
\hline NoLink-NoSto & - Supply area is not interconnected \\
\hline LinkHVDC & - $\quad$ Storage is possible \\
\hline NoLil & $\begin{array}{l}\text { - } \quad \text { Supply area is not interconnected } \\
\text { - } \quad \text { Storage is possible }\end{array}$ \\
\hline LinkHVDC\&PL-Sto & $\begin{array}{l}\text { - Supply area is interconnected via } \\
\text { HVDC and } \mathrm{GH}_{2} \text { Pipelines with low } \\
\text { investment cost based on }[18,19] \\
\text { - Storage is possible }\end{array}$ \\
\hline $\begin{array}{l}\text { LinkHVDC\&PL-Sto- } \\
\text { Cost50\%- }\end{array}$ & $\begin{array}{l}\text { - Supply area is interconnected via } \\
\text { HVDC and } \mathrm{GH}_{2} \text { Pipeline with low } \\
\text { investment cost based on }[18,19] \\
\text { - Storage is possible } \\
\text { - } 50 \% \text { cost reduction for Hydrogen } \\
\text { Electrolysis system and Fuel Cell } \\
\text { technology }\end{array}$ \\
\hline
\end{tabular}


For the purpose of developing an optimistic scenario for renewable supply, associated cost reduction and efficiency improvement of renewable technologies are assumed to be high, while the backup technology serves as an expensive option. HVDC transmission technology associated costs are determined based on the $800 \mathrm{kV}$ HVDC transmission technology presented in [18]. In the base case, capital cost of the electrolysis system is determined based on the future electrolysis technology represented in [20]. Fuel cell technology investment cost is assumed to be 450 (US2000\$/ $\mathrm{kW}$ ) based on the prospective cost reduction trends described in [21]. Pipeline Investment cost is estimated based on the projected specific capital costs proposed by T.Dreier in [19].

The role of a powerful grid in a renewable-based electricity supply system can be analyzed by comparing the results of the scenario "LinkHVDC-NoSto" with the extreme case, where the supply area is not interconnected (Scenario "NoLink-NoSto"). The effect of storage systems are analyzed in two different scenarios: "LinkHVDC-Sto"' and "NoLink-NoSto". The role of hydrogen as a transport medium where the primary energy resource is remotely located and is in excess of local demand is studied in scenarios "LinkHVDC\&PLSto"' and 'LinkHVDC\&PL-Sto-Cost50\%-"'. In these scenarios the supply area is interconnected via HVDC as well as $\mathrm{GH}_{2}$ pipelines, and hydrogen can be used for stationary power production.

Total installed capacity and produced electricity for ideal scenarios, presented in Table 1 , are shown in figures 5 and 6 respectively. It can be realized that the renewablebased power supply system can not operate as efficient as a controllable fossil fuel-based energy system. In the most efficient cases (Scenarios "LinkHVDC-Sto"' and “'LinkHVDC\&PL-Sto-Cost50\%-”'), excess production reaches about $28 \%$ of the total produced electricity. This represents a share of produced electricity, which neither can be utilized at the instant of generation nor can be economically stored for later usage.

In order to have the same contribution share of renewable sources as in a globally interconnected structure realized in the "LinkHVDC-NoSto"' scenario, significant level of backup power is installed in the "NoLink-NoSto" and "NoLink-Sto" scenarios. Excluding the transport possibility necessitates the contribution of backup power as $26 \%$ of the total installed capacity, and the excess production share increases to $50 \%$. The reservoir capacity significantly increases in the "NoLink-Sto" to provide inter-seasonal balancing as the renewable electricity in excess of local demand may not be transported at the instant of production for wide-are balancing purposes. The influential role of a powerful transmission network can be realized as it provides the infrastructure to achieve smoothing effects among weather dependent renewable power generation units to make the most promising sites accessible for wide-area usage. It also powerfully integrates the dispatchable fossil fuel technology for instant load following purposes and backup applications.

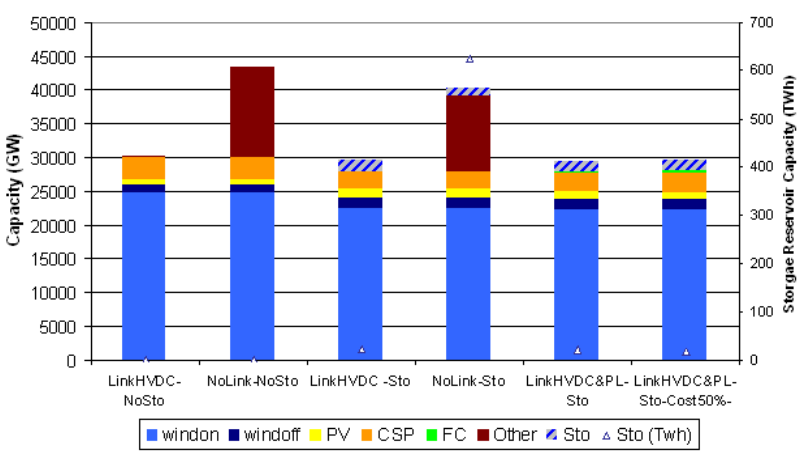

Figure 5. Total power plant Capacity in Ideal Scenarios

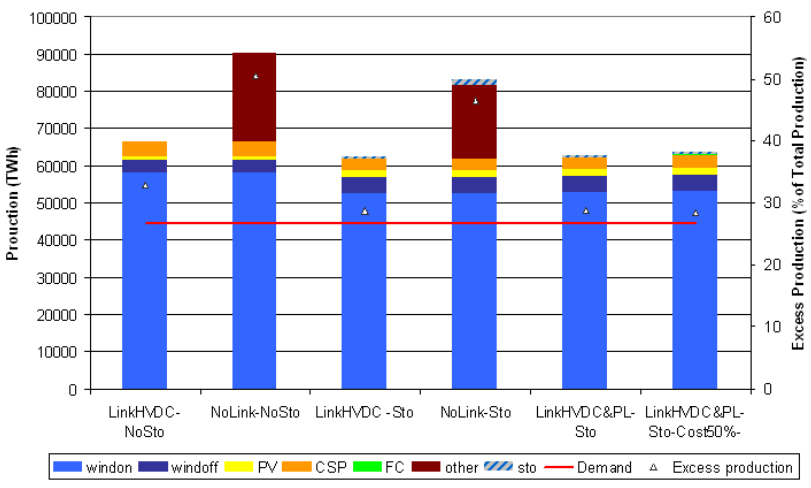

Figure 6. Total produced electricity in Ideal Scenarios

In the scenarios "LinkHVDC-NoSto"' and "LinkHVDCSto" about $60 \%$ of the total produced electricity is interregionally transmitted via HVDC system. Ideal energy flows are visualized in Fig.7 for the scenario "LinkHVDC-NoSto"'. One noticeable feature is the major energy flows to the highly populated areas of South East Asia and Eastern China. Australia acts as one of the main exporting regions due to its high technical potential of renewable electricity in excess of local demand. Wind electricity is as well imported from Alaska through Far East to Eastern China. In the European interconnected area major flows take place from Britannia to Western Europe and North Africa through Southern Europe to Western and Central Europe. Other interesting feature is the import of wind electricity from Canadian offshore sites to Western U.S.. Significant energy flows from Argentina with high technical potential of wind electricity to Northern part of South America are also realized from the optimization.

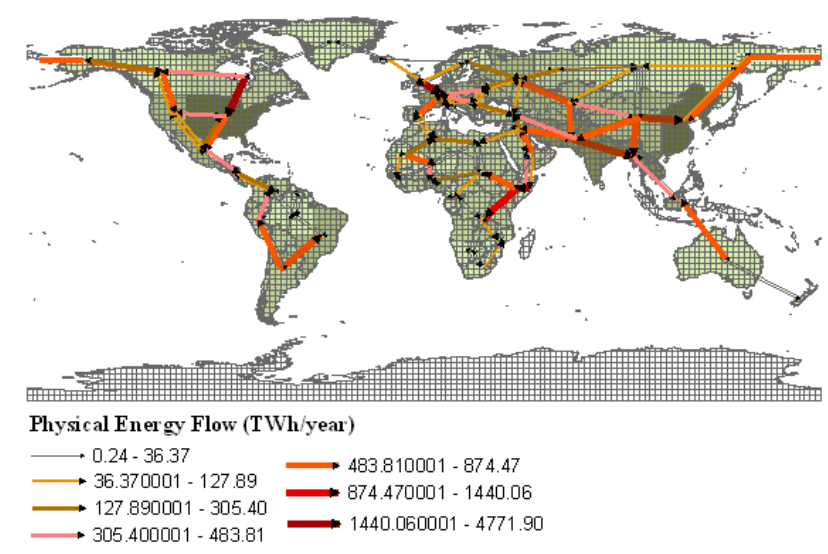

Figure 7. Ideal Energy Flows (Scenario“'LinkHVDCNoSto”) 


\section{B. $\mathrm{CO}_{2}$ Stabilization Scenarios}

The main target here is to realize the optimal structure of a power system and ideal contribution shares of renewable energy sources in a $\mathrm{CO}_{2}$ limited scenario and for different boundary conditions. In the analyzed $\mathrm{CO}_{2}$ mitigation Scenarios, conventional power plants as well as renewable-based technologies are considered. In all scenarios the $\mathrm{CO}_{2}$ reduction target proposed by International Panel on Climate Change Working group 1 (IPCC WG1) for the stabilization of $\mathrm{CO}_{2}$ at $550 \mathrm{ppmv}$ is implemented with inclusion of where flexibility [22]. Analyzed scenarios and underlying assumptions are briefly described in Table 2 .

Table 2: $\mathrm{CO}_{2}$ stabilization scenarios and underlying assumptions

\begin{tabular}{|c|c|}
\hline Scenario & Underlying Assumptions \\
\hline $\begin{array}{l}\text { Mitigation-Link-Sto } \\
\text { (Base case) }\end{array}$ & $\begin{array}{ll}- & \text { Total } \mathrm{CO}_{2} \text { limit based on } \\
& \text { IPCC WG1 Scenario [22] } \\
\text { - } & \text { Supply are is interconnected } \\
& \text { via HVDC } \\
\text { - } & \text { Possibility for storage }\end{array}$ \\
\hline $\begin{array}{l}\text { Mitigation-Link-Sto } \\
70 \% \mathrm{R}\end{array}$ & $\begin{array}{ll}\text { - } & \text { 70\% of total demand is } \\
\text { Satisfied with renewables }\end{array}$ \\
\hline $\begin{array}{l}\text { Mitigation-Link-Sto } \\
70 \% \mathrm{R}-1 / 2 \mathrm{PV} \\
\text { \&2/5CSPCt }\end{array}$ & $\begin{array}{l}\text { - } \\
\text { 70\% of total demand is } \\
\text { satisfied with renewables } \\
\text { PV technology associated costs } \\
50 \% \text { reduced compared to Base } \\
\text { - CSP associated costs } \\
\text { 60\% reduced compared to Base }\end{array}$ \\
\hline
\end{tabular}

Associated long term efficiency improvements and realizable cost reductions for renewable technologies are approximated based on [23,24]. Capital costs of conventional technologies are considered to be stabilized at current levels [25]. Therefore, no significant cost reduction trend is assumed for them. Fuel prices are estimated based on the average values given in [25]; no assumption is made here for determination of long-term trend of fossil fuel prices. Techno-economic parameters of technologies are represented in Table 3.

Table 3: Techno-economic parameters of power plants $[23,24,25]$

\begin{tabular}{|c|c|c|c|c|}
\hline Tech. & $\begin{array}{l}\text { Capital Cost } \\
\text { (US2000\$/k } \\
\mathrm{W}_{\mathrm{el}} \text { ) }\end{array}$ & $\begin{array}{l}\text { Fix Cost } \\
\text { (US2000\$ } \\
\left./ \mathrm{kW}_{\mathrm{el}} / \mathrm{a}\right)\end{array}$ & $\begin{array}{l}\text { Variable } \\
\text { Cost } \\
(\mathrm{US} 2000 \$ / \\
\left.\mathrm{kWh}_{\mathrm{el}}\right)\end{array}$ & $\begin{array}{l}\text { Effici } \\
\text { ency }\end{array}$ \\
\hline Wind onshore & 750 & 20 & 0 & \\
\hline $\begin{array}{l}\text { Wind } \\
\text { offshore }\end{array}$ & 1300 & 40 & 0 & \\
\hline Photovoltaic & 2200 & 12 & 0 & 0.25 \\
\hline $\begin{array}{l}\text { Solar } \\
\text { Thermal }\end{array}$ & 1840 & 18 & 0 & 0.25 \\
\hline $\begin{array}{l}\text { BGCC } \\
\text { (Biomass } \\
\text { Gasification } \\
\text { Comb. Cycle) } \\
\end{array}$ & 1612 & 32.2 & 0.024595 & 0.38 \\
\hline $\begin{array}{l}\text { Coal } \\
\text { (Pulverised } \\
\text { Fuel) } \\
\end{array}$ & 1300 & 23.4 & 0.016862 & 0.43 \\
\hline $\begin{array}{l}\text { CCGT } \\
\text { (Conv. Gas } \\
\text { Comb. Cycle) }\end{array}$ & 750 & 13.5 & 0.0273634 & 0.58 \\
\hline $\begin{array}{l}\text { GT } \\
\text { (Gas Turbine) }\end{array}$ & 400 & 8 & 0.047601 & 0.33 \\
\hline Nuclear & 1500 & 30 & 0.014543 & 0.35 \\
\hline
\end{tabular}

\begin{tabular}{|l|l|l|l|l|}
\hline (Adv. LWR) & & & & \\
\hline $\begin{array}{l}\text { Pumped } \\
\text { Storage }\end{array}$ & 1393 & 10 & 0 & 0.80 \\
\hline
\end{tabular}

Aggregated optimization results for the installed capacity and produced electricity are shown in Figures 8 \& 9 . Implementing the $\mathrm{CO}_{2}$ reduction target, the cost optimal solution is characterized by the contribution of nuclear technology as a major base load power plant while gasfired units and wind parks provide the peak demand. However, wind energy has a minor share in this scenario. In the scenario 'Mitigation-Link-Sto-70\%R", wind energy contributes as the only renewable technology within the interconnected supply area. Although $70 \%$ of the total electricity demand is satisfied with wind power, installed capacity of conventional technologies only reduces $37 \%$ compared to the base case. This can be realized as for the operation of power systems with significant amounts of variable renewable sources, the importance of conventional generation will remain or may increase even further to guarantee a reliable power supply. Highly intermittent nature of this primary energy resource leads to the system inefficiency due to the resulted excess production at the level of $17 \%$ of total produced energy. The overall system cost is rather doubled compared to the base scenario.

With further cost reduction assumed in the last mitigation scenario, the cost optimal solution is characterized by a diversity of renewable technologies comprising wind onshore, PV, and concentrating solar power systems as well as nuclear technology and gas-fired power plants. The excess production share decreases to $15 \%$ due to the contribution of solar power systems and reduced capacity of wind energy converters.

In "Mitigation-Link-Sto" scenario, characterized by a minor share of renewables, the interregional transport capacity only reaches about $1 \%$ of total transport capacity in the "LinkHVDC-Sto", scenario. This share increases to $20 \%$ and $18 \%$ in scenarios "Mitigation-Link-Sto70\%R" and "Mitigation-Link-Sto-70\%RPV1/2\&2/5CSPCt”, respectively.

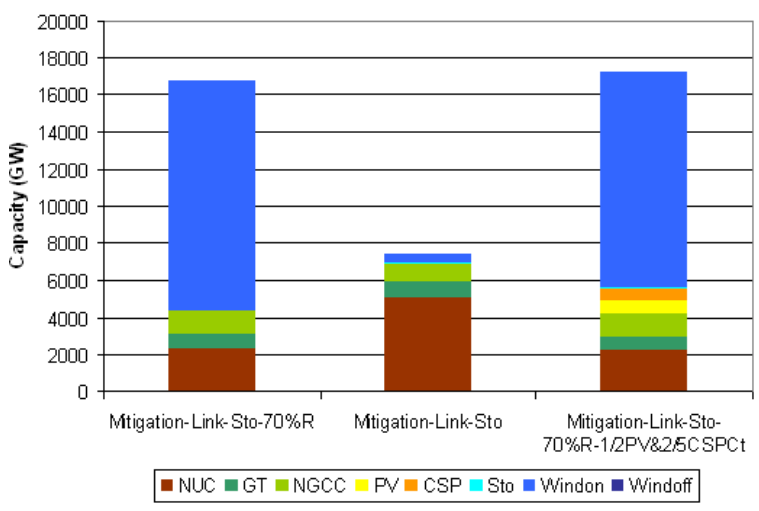

Figure 8. Total power plant Capacity in Mitigation Scenarios 


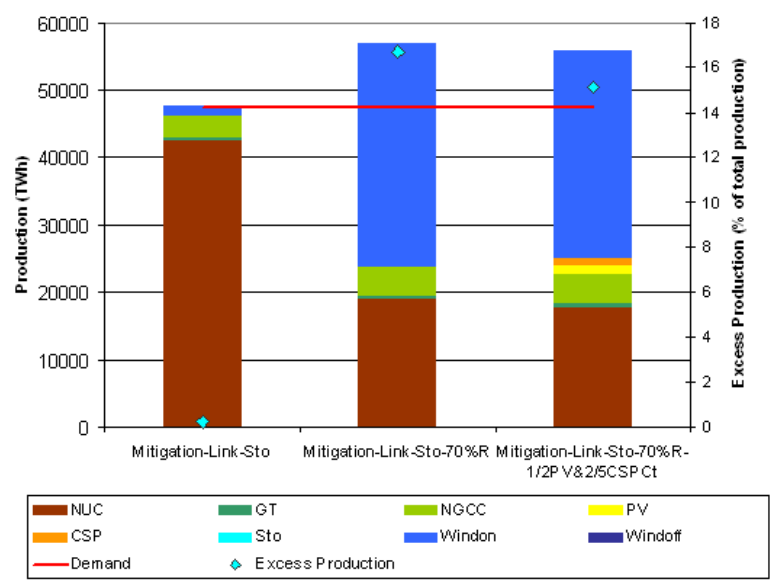

Figure 9. Total produced electricity in Mitigation Scenarios

\section{Conclusion}

In this study, a multi-regional energy system model for the analysis of long term evolution of the global power supply system has been developed. The modeling approach, presented here, is the combination of an adequately precise geographical coverage with high temporal resolution. It allows for representing the optimal power generation capacities, promising sites for installation of renewable technologies as well as interregional transport.

It may be argued that the applied simulation technique is adequately efficient to properly mimic the geographical dependencies of energy supply and demand as well as short term intermittent patterns of renewable sources. This sets up a reliable analysis tool, allowing answers to the questions associated with renewable electricity supply without resorting to unverified assumptions.

Simulation results are presented for different incarnations of an ideal $100 \%$ renewables scenario as well as global $\mathrm{CO}_{2}$ stabilization scenarios. It has been discussed that a renewable-based power supply system suffers from rather high inefficient operation compared to a controllable fossil-fuel based energy system. However, in a globally interconnected structure via HVDC transmission systems and/or $\mathrm{GH}_{2}$ pipelines, required backup power and storage systems reduce significantly. This can be realized as it provides the infrastructure to achieve smoothing effects among weather dependent renewable power generation units. It makes the most promising sites for renewable electricity production accessible for wide-area usage and powerfully integrates the dispatchable fossil fuel technology for instant load following purposes and backup applications. Therefore, the overall installed capacity and excess production share reduce significantly compared to the isolated power supply systems with exclusion of long distance transport possibility.

In other sets of scenarios, the optimal structure of a $\mathrm{CO}_{2}$ limited power supply system is studied. In base scenario with very low contribution share of renewables, the interregional transport significantly reduces compared to the ideal scenarios. Sensitivity of the results to the
Photovoltaic and concentrating solar power systems associated costs are as well investigated.

\section{Acknowledgement}

Authors wish to express their gratitude to transmission system operators that have given hourly electrical load profiles. Special acknowledgement goes to O.Brückl, T.Dreier, M.Biberacher, and N.Heitmann as frontiers of current research topic at Institute for Energy Economy and Application Technology and Max Plank Institute for Plasma Physics. Funding from BMW AG is gratefully acknowledged.

\section{References}

[1] Torsten Haase Anforderung an eine durch Erneuerbare Energien geprägte Energieversorgung- Untersuchung des Regelverhaltens von Kraftwerken und Verbundnetzen, Dissertaion, Faculty of Electrical Engineering, University of Rostock, 2006

[2] Nina Heitmann, Solution of Energy Problems with the help of Linear Programming, Master Thesis, University of Augsburg, 2005

[3] Nina Heitmann and Thomas Hamacher, Stochastic Model of German Electricity System, Optimization in the Energy Industry, Energy Systems, Springer, doi:10.1007/978-3-54088965-6, 2008, p. 365-385

[4] Richard E. Rosenthal, GAMS A User's Guide, GAMS Development Corporation, Washington, DC, 2008

[5] W.E. Han and D.J. Ward, Final Report on EFDA TIMES Model Electricity Sector Update Task, Technical Report, EURATOM/UKAEA Fusion Association, UK, 2007.

[6] M. Labriet, R. Loulou, A.Kanudia, Global Energy and $\mathrm{CO}_{2}$ emission scenarios: analysis with a 15-regions world MARKAL model, Prefinal version of the paper, The Coupling of Climate and Economic Dynamics, Essays on Integrated Assessment, Advances to Global Change Research, Vol. 22, Springer Academic Publishers, 2005.

[7] Markus Biberacher, Modeling and Optimization of Future Energy System using Spatial and Temporal Methods, PhD Thesis, Institute for Physics, Experimental Plasma Physics, University of Augsburg, Germany, 2004.

[8] J.K.B.Bishop, T.Potylitsina, W.B. Rossow, Documentation and Description of Surface Solar Irradiance Data Sets Produced for SeaWifs, Department of Applied Physics of Columbia University, EO Lawrence Berkeley Laboratory, NASA/Goddard Institute for Space Studies, USA, 2000.

[9] Peter Tzscheutschler, Global Technical Potential of Solar Thermal Electricity, PhD Thesis, Institute for Energy Economy and Application Technology (lfE), Technische Universität München, Germany, 2005.

[10] World Wind Atlas, Sander \& Partner GmbH, http://www.sanderpartner.ch.

[11] V90-3.0 MW An efficient way to more power; Vestas Wind Systems A/S, http://www.vestas.com.

[12] Oliver Brückl, Global Technical Potential of Wind Electricity, Final Report prepared for BMW AG Study: Gewinnung und Anwendung von Sonnenenergie, Institute for Energy Economy and Application Technology, Technische Universität München, Germany, 2005.

[13] IIASA Greenhouse Gas Initiative (GGI) database, http://www.iiasa.ac.at/web-apps/ggi.

[14] European Network of Transmission System Operators (ENTSOE) Statistical Database, http://www.entsoe.eu/resources/publications.

[15] UK National Grid Company web site, http://www.nationalgrid.com/uk 
[16] Yvonne Zickermann, Approximation of Typical Load Curves for Different Continents and Climate zones, Studienarbeit, Institute for Energy Economy and Application Technology (lfE), Technische Universität München, Germany, 2005.

[17] Estonian Power Transmission System Operator: Elerging OÜ, http://www.elering.ee

[18] Ultra High Voltage DC Systems, ABB Power Technologies AB Grid Systems-HVDC,

http://www.abb.com/hvdc

[19] J.Angloher, Th. Dreier, Techniken und Systeme zur Wasserstoffbereitstellung, Institute for Energy Economy and Application Technology (lfE), Technische Universität München, 1999.

[20] Johanna Ivy, Summary of Electrolytic Hydrogen Production, Milestone completion Report, National Renewable Energy Laboratory, 2004.

[21] J.Halliday, A.Ruddell, Fuel Cells: Providing heat and power in the urban environment, Tyndall Centre for Climate Change Research, 2005.

[22] Alan Manne and Richard Richels, On stabilizing $\mathrm{CO}_{2}$ concentrations-cost-effective emission reduction strategies, International Journal of Environmental Modeling and Assessment, 2, 1997, pp. 251-265.

[23] W.E. Han and D.J. Ward, Final Report on EFDA TIMES Model Electricity Sector Update Task, Technical Report, EURATOM/UKAEA Fusion Association, UK, 2007.

[24] Power Plant Database, Institute for Energy Economy and Application Technology (lfE), Technische Universität München [25] Nuclear Energy Agency and Inernational Energy Agency, Projected costs of generating Electricity, 2005.

[26] Gregor Czisch, Szenarien zur zukünftigen Stromerzeugung, PhD Thesis, Faculty of Electrical Engineering, University of Kassel, Germany.

[27] World Energy Outlook, International Energy Agency, 2006.

[28] Energy Information Administration International data, http://www.eia.doe/fuelelectric.html 